\title{
A Comprehensive Student-Based Analysis Of Hybrid Courses: Student Preferences And Design Criteria For Success
}

Joseph B. Mosca, Monmouth University, USA Daniel R. Ball, Monmouth University, USA

John S. Buzza, Monmouth University, USA

David P. Paul, III, Monmouth University, USA

\begin{abstract}
Online leaning in all forms has become the largest segment of growth in the education model over the last 10 years. Our paper focuses on the general area of computer-assisted learning, a method that uses interactive software as an aid to learning, and more specifically on blended courses courses that are taught congruently online and in a traditional setting. Our paper examines the methodology of such innovation and details the steps necessary to institute such a program in main-stream teaching. Our paper will also help make more clear the learning intentions and show how students can achieve success while instructors take advantage of new-age methods to help them become more versed in the art of teaching. We will identify the necessary steps that students must take prior to enrolling in these courses, examine the requirements, and commitments that institutions must make to implement such a curriculum and show how the instructors must prepare themselves for the rigors that lie ahead in making this course both enjoyable and educational. A comprehensive survey and statistical analysis was conducted and the results presented in this paper to support any conclusions and recommendations. E-learning is offered in many forms throughout the world. Today, you can secure a bachelors, masters or even doctoral degree totally online. Students will continue to supplement a very busy work/life balance with online education, therefore we feel our paper addresses these concerns now and in the future and show not only the importance of this methodology, but how a simple seamless integration of this process is possible for institutions of higher learning.
\end{abstract}

\section{INTRODUCTION}

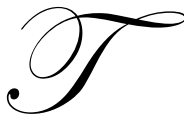

he average 3-credit course consists of 1.25 contact hours twice a week, or once a week for 2.50 contact hours; both for a 15 week semester. When constructing a blended (i.e., hybrid) course which requires that classroom time is reduced by half, the instructors need to re-examine what teaching techniques are most appropriate for the new teaching format. What this entails is an entirely new course design (Bates and Watson, 2008), which has been hypothesized to "provide moderate to high degrees of access and flexibility while offering the potential for moderate to high dialogue and low to moderate structure" (Millison and Wilemon, 2008). This paper reviews some "how to" suggestions with respect to designing such courses, and presents surveyed results describing how students relate to blended classes.

A traditional method of teaching a course involves the instructor transmitting knowledge and information to the students. The instructors spend a considerable amount of time in developing lecture materials in an attempt to enhance the material to maintain student focus and spark interest. This approach is called "face-to-face" teaching and is familiar to students because of its use in grades K-12. Another term for "face-to-face" instruction is "direct instruction." A lecture can be called a "direct format approach to teaching" where the teacher tells the learner what they need to know. Yelon cites (Clark, 2001) and introduces a different approach - guided discovery. In the guided discovery approach, students learn on their own by observing, asking questions, and conducting activities, all of which are coupled by feedback from the instructor (Yelon, 2006). The guided discovery approach is a preferred approach for blended courses because it allows students to learn on their own by observing. 
What these researches have observed from the guided discovery approach is that students can learn at their own pace and can review the material as they see fit. This current research effort used the guided discovery approach through the design of interactive, animated presentation slides. The media used for this study were animated PowerPoint slides whereby the learner had to advance the PowerPoint slides by clicking the mouse to advance the text on each slide. For example, the slide content might contain the following:

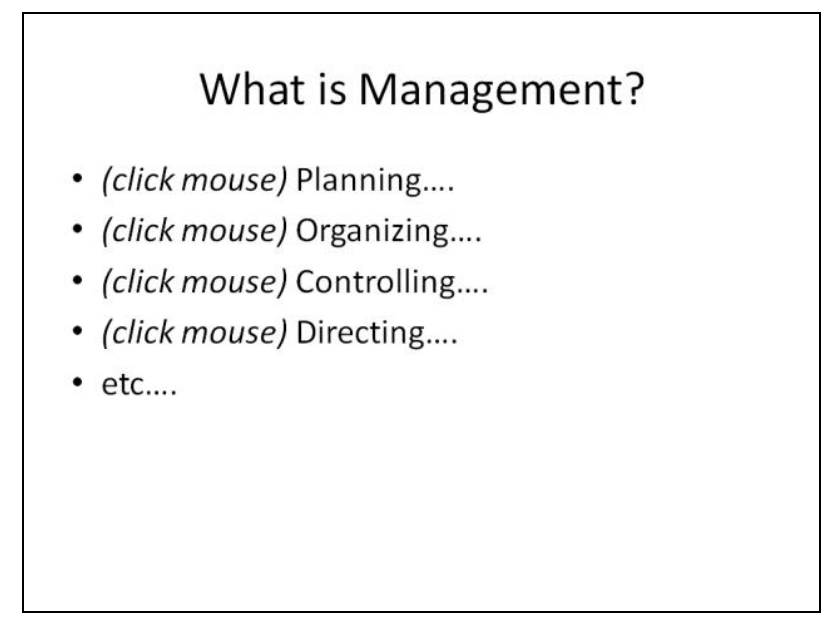

As one can note from the above example slide, the student can study the slide content but must also interact with the media to facilitate the learning process. Therefore, the responsibility for learning is with the student. We must keep in mind that the instructor preparing the on-line lessons must take responsibility for teaching the concepts in a comprehendible fashion that will maintain the students' focus.

According to D'Orsie and Day (2006), the following ten guidelines can assist in the design of blended courses:

1) Identify all the prerequisites the students will require before taking the course. Not only should these prerequisites be identified, but elements such as access to a computer and e-mail will be required when the on-line lessons will be available for viewing. Also, will the lesson be time sensitive or available whenever the students want to log-on?

2) Clarify the computer requirements and capacity for the University, including the use of a variety of programs such as electronic classroom programs (e.g., Blackboard, eCampus) or appropriate versions of Microsoft Office. In addition, the students may require access to DVD-viewing devices.

3) Establish a support system for students to obtain help when needed, such as a "Help Desk," whereby questions can be answered. The course listing must indicate on which days the class meets in the classroom and when lessons are available on-line. The instructor should notify all enrolled students of course guidelines.

4) The instructor must be specific as to how tests will be taken by the students, defining if tests will be on-line or in the classroom. A copy of the course syllabus should be accessible on-line as well.

5) The instructor, without provocation, must define the policies for the course such as: when the last day is to register for the course or the attendance rules. For example, if a student misses the first two weeks of class it would be difficult for that student to catch up on classroom activities.

6) What are the participation policies? The system must be capable of providing the instructor with an audit on each student and illustrate when each student logs in, for how long, and what course content the student reviewed. The instructor must be clear to students as to what portion of the grade on-line participation counts towards the final grade. Therefore, the instructor must define the difference between the classroom grade and the on-line grade. 
7) A course schedule must be designed depicting what will take place during classroom time. If class activities are to be used, it is suggested that the class be divided into groups (not more than five students per group), and a schedule devised depicting which groups will lead discussions, on which days, what topics will be discussed, and the approximate time that each group is allowed to complete their project.

8) Preparing the syllabus must be done carefully to define and communicate requirements in detail. One must keep in mind that the time spent in the classroom will be cut in half; therefore, effective time management becomes imperative.

9) When a class roster is available, it is helpful for the instructor to e-mail the students welcoming them and providing a general idea as to what will be taking place, as well as general course information (e.g., "Help Desk" number; instructor's e-mail address; how to access the on-line course content; computer requirements). In addition, students should be asked to provide general information to the instructor (e.g., study interests, computer skills).

10) Begin to build an on-line community by sharing the e-mail addresses with all of the students. Many students have their photos posted on their web-sites and this can serve as a good ice-breaker.

Terry (2007) points out how far on-line instruction has come over the years and, as of now, this mode of instruction has become a major part of higher education. He cites that the Department of Education estimates an increase of 100 college courses are added to an on-line format each month (National Center for Education Statistics, 2001). There are some advantages to the on-line mode, as it partially replaces classrooms and allows students to work at their own pace. There can be drawbacks, however, if the instructor lacks sophistication and creativity in creating the on-line lessons, and one must get accustomed to creating an on-line lesson that does not follow a lecturing format. Graduate students and working professionals who are limited in classroom time can benefit from hybrid courses and at the same time reap the benefits of classroom interactions (Millison and Wilemon, 2008).

William (2006) talks about assessment and learning, and how instructors can strategize to implement approaches for quality teaching and learning. These strategies can be applied to hybrid course construction as follows:

- $\quad$ Clarify the learning intentions and put forth how students can achieve success;

- Design effective classroom discussions;

- When the instructor provides feedback, respond in a positive sense to motivate students to move forward;

- $\quad$ Engage the students in the learning process so they become owners of their learning; and

- Allow students to learn from each other.

According to Young (2002), the hybrid mode and degree programs offering this approach provide the learner with, as he puts it, "the best of both worlds". This result is true because the learner has the ability to retrieve their on-line lesson at their convenience and still be able to take part in classroom activities.

El Mansour, Mupinga and Davidson (2007) explain how many terms there are for on-line instruction such as: e-learning, internet learning, distributed learning, network learning, tel-learning, virtual learning, or web-based learning. All of these terms relate to an instructional mode whereby the learner is geographically separated from the instructor, and some of the lessons are on-line and some are face-to-face. Depending on the creativity of the instructor, the on-line delivery can be composed of a combination of audio, video, color, graphics, and animation. All of these delivery methods, when used properly, can stimulate the learner and help the student maintain focus. There seems to be a move towards on-line instructions of all varieties; overall on-line enrollment has increased from 1.98 million in 2003 to 2.35 million in 2004 (El Mansour, Mupinga and Davidson, 2007).

It has been mentioned in the literature how hybrid courses may contain graphics and videos. Penrose (2006) points out that some students prefer learning through visualization, and goes on to say that many learn effectively through a combination of verbal and visual approaches. Penrose's list of how to use visualization in hybrid course design includes the following: 
- $\quad$ Photographs to assist realism;

- $\quad$ Drawings (e.g., blueprints);

- Diagrams that assist the illustration of flow and direction;

- $\quad$ Graphics that enhance text;

- Videos that reinforce a concept; and

- $\quad$ Films that incorporate and show how concepts are used in real-life settings.

Hiltz and Turoff (2005) define the following driving societal forces that support on-line learning:

- $\quad$ Flexibility that the learners have to be able to incorporate education with life and employment;

- $\quad$ The learning effectiveness of blended courses being equal to, or sometimes better than, direct face-to-face instruction; and

- $\quad$ Blended and all on-line courses keep colleges and universities competitive.

According to Gargiulo and Metcalf, (2010), computers can increase student performance on standardized tests and reduce the amount of time required to learn basic skills. In addition, technology can increase student motivation and improve self-concept. Technology also had a positive impact on students' independence and feelings of responsibility for their own learning. One of the most powerful inclusions of technology and teaching is with students with disabilities, allowing them to spend less time in the classroom and be able to study and learn from home.

\section{THE STUDY}

This study was conducted at a private university in the Eastern part of the United States. The institution is medium in size with a total enrollment of approximately 5,800 students, of which 1,200 are graduate students. This university is classified as a comprehensive teaching institution. The purpose of this study was to determine student satisfaction when attending a hybrid course and to answer the following questions:

1) How many hybrid courses have you completed prior to this course?

2) Would you take another hybrid course?

3) Would you prefer that this course was hybrid or traditional?

4) Have you ever had an online oral lesson?

5) In a hybrid course, do you like the flexibility of choosing when and how quickly you learn the material?

6) Could you effectively follow these oral presentations?

7) How well were the video-clips synchronized with the oral presentations?

8) Did you feel that you had adequate access to the professor?

9) How effective was discussion while not in the classroom?

10) Was your interest maintained while not in the classroom?

11) Did you have the sense of a student community while not in the classroom?

12) Where did you gain access to the internet?

13) How effective was the classroom lecture?

14) During classroom time, would you prefer: (1) more lecture time, (2) the same amount of lecture time, or (3) less lecture time?

15) On the day the class meets, would you prefer: (1) more student presentation time, (2) the same amount of student presentation time, or (3) less student presentation time?

16) Would you like short case analyses to be part of the class time?

17) Would you like problem solving exercises to be part of the class time?

18) Would you like open discussion with the professor to be part of the class time?

19) In your opinion, what is the minimum level for a hybrid course: (1) 100 (i.e., freshman), (2) 200 (i.e., sophomore), (3) 300 (i.e., junior), (4) 400 (i.e., senior), or (5) graduate level?

The surveys were administered to participating classes of 26 mixed freshmen/sophomores, 61 mixed juniors/seniors, 94 seniors, and 29 graduate students. A complete tabulation of survey results for each question, including graphical representations of the results, is included in Appendix A. 


\section{STUDY RESULTS}

The general results are summarized using the following categories: (1) hybrid course experience and preference; (2) quality and effectiveness of online component; (3) class time design; and (4) appropriate class level. A summary of the key findings for each category is presented below.

\section{(1) Hybrid Course Experience and Preference (Questions 1-5)}

The initial portion of the survey addressed the overall hybrid experience level that students had prior to the course currently being taken (i.e., the one in which the survey was administered), as well as their general opinion towards taking a hybrid course in the future. As shown from Question 1, the number of prior hybrid courses increased as the academic year increased for the undergraduate students (i.e., freshmen, sophomores, juniors, and seniors), with the percentage of students without any prior hybrid experience decreasing from $88.46 \%$ as freshmen/sophomores to $60.64 \%$ as seniors. This result makes sense because the more experienced students had additional opportunities to have taken hybrid courses. The graduate students, however, are generally new to the hybrid course experience, with $93.10 \%$ having no prior hybrid experience. This lack of hybrid course experience is likely because many of the graduate students are part-time students and the hybrid format was not as widely used when they were undergraduate students. Furthermore, the majority of the students at all levels (except seniors) did not have any experience with online oral lessons (Question 4); 50\% of the seniors had this experience.

The results of Questions 2 and 3 suggest that most students would take a hybrid course again and, in fact, prefer hybrid courses to the traditional form of teaching. This result was generally independent of the academic experience level (i.e., almost identical percentage distribution). It should be noted that, although only three students claimed that they would probably not take another hybrid course, these respondents all came from the same class ( $4.92 \%$ of the juniors/seniors class). This mixed junior/senior class also showed the highest percentage (18.33\%) of respondents who preferred the traditional format. It is possible that this course may simply not be as conducive to the hybrid structure. To examine this possibility, a follow up study was conducted: of the $18 \%$ of students who preferred the traditional method of instruction approximately, $10 \%$ were interviewed to find why this preference. The question was posed by a graduate assistant to avoid the possibility of the students who were being interviewed feeling intimidated by being questioned by an instructor. The majority responded that they had to adjust to self study and would prefer taking quizzes after a lecture rather than applying previously learned concepts to case studies. Also, the instructor reviewed student GPAs of the students questioned and found these students to be within the lower percentile. It was therefore concluded that this minority result was most probably a reflection of the academic achievement level of a particular group of students, and not an effect which was due to the course format itself.

As expected, Question 5 indicated that the flexibility provided by the hybrid course is recognized positively by the majority of the students, with a minimum positive response of $91.80 \%$ (seniors). This flexibility is especially noted by the graduate students $(100.00 \%$ of the graduate students recognized this flexibility) who are oftentimes attending the university while also trying to balance both family and full-time job demands.

\section{Quality and Effectiveness of Online Component (Questions 6-12)}

Although the majority of the students did not have any experience with online oral lessons (Question 4), the majority of the students were able to effectively follow the oral presentations designed for these courses (Question 6). Furthermore, the majority of the students reported that the video clips were synchronized with the oral presentation either moderately or very well (Question 7). Therefore, the technical aspects of these hybrid courses appeared to properly convey the teaching objectives to the students.

A primary area challenge with hybrid courses is ensuring quality education when the student is not in the classroom. Although the majority of the students agreed that they had adequate access to the professor (ranging from $83.6 \%$ for juniors/seniors to $96.8 \%$ for seniors-only courses in Question 8), challenge areas included having effective discussions (see Question 9, where the range of students judging non-classroom discussion to be either fair or poor ranged from $3.5 \%$ for graduate students to $14.8 \%$ for mixed juniors and seniors), maintaining interest (see 
Question 10, where the range of students who felt that their maintained interest while not in the classroom was maintained only fairly or poorly ranged from $3.9 \%$ for mixed freshman and sophomores to $13.1 \%$ for mixed juniors and seniors), and establishing a sense of student community (see Question 11, where students who responses of "maybe", "no" or "strongly no" to the query "Did you have a sense of a student community while not in the classroom" was approximately $40 \%$ of each undergraduate class and $31 \%$ of the graduate class). These results suggest that improvements could enhance the hybrid experience. The responses to Question 12 indicated that all of the students had internet access, with the overwhelming majority obtaining access at either home or school, perhaps accessing simultaneously or more regularly would help to improve these issues.

\section{Class Time Design (Questions 13-18)}

This final portion of the survey helped to provide insights into how best to utilize the time that the class physically meets in a traditional classroom. Although the results of Question 13 indicate that a majority of the students rated that class time was used either very or moderately effectively, there were still some that scored class time usage as only fair (including $11.54 \%$ of freshmen/sophomores and $9.84 \%$ of juniors/seniors). Questions 14 and 15 suggest that, generally, most students are happy with the amounts of lecture and presentation time. However, the mixed junior/senior class generally preferred more lecture time and less student presentation time. Follow-up interviews with 210 undergraduate students in mixed junior and senior classes in blended courses found that the preference for more lecture time opposed to presentation time was related to a feeling on the part of the students that more class time used by the professor to lecture would result in spending less time in preparation for class presentations. This finding is confirmed in Question 16 which indicate favorable assignments; the less time students spend on assignments the more they are accepted. What this means is that students prefer assignments that are in smaller portions, for they can complete them faster and claim they are then motivated to do more work, for it gives them a sense of completing more work.

Other potential class time changes include the inclusion of short case analyses, problem solving exercises, or open discussions. Based on the results of Question 16, the majority of the students at all class levels desire short cases to be included in the class time. This result is especially high for the graduate students $(89.66 \%$ recommending case studies), possibly because most of these students are also working full-time and cases can provide them with solid real world examples and enable them to more easily apply the course findings to their own jobs. An alternative rationale for the strong preference of graduate students for more case studies could simply be that graduate students are more accustomed to this teaching/learning approach, as the case teaching method is used more often in graduate classes than in undergraduate classes. Since students could have responded that more lecture time was preferred, these results can be interpreted as strengthening the conclusion that more "action oriented" approaches are preferred to the traditional lecture format often employed. Similarly, the majority of students at all class levels desired the inclusion of problem solving exercises during class time (Question 17). Finally, the limited amount of class time does leave less time for open discussions with the professor. The results of Question 18 indicated a significant percentage of respondents in all class levels (with a minimum of $91.49 \%$ of seniors) that would prefer more open discussion time with the professor.

\section{Appropriate Class Level (Question 19)}

The final survey question was aimed at determining, from the students' point of view, what the most appropriate class level is for a hybrid course. The results of Question 19 displays a shift to higher class level recommendations as the polled class level increases. For example, $80.00 \%$ of the freshmen/sophomores responded that a 200 -level course was the minimum class level for a hybrid course. However, only $6.90 \%$ of the graduate students believed that a 200-level course was suitable as a hybrid. So it appears that, although each group is generally comfortable with the hybrid course structure, it is not believed that less experienced students are ready.

\section{(5) Statistical Significance of Overall Assessment}

A comprehensive statistical analysis using hypothesis testing was conducted to determine the overall student preferences and future opinions regarding hybrid courses. For this analysis, Questions 2 and 3 were examined in further detail to determine their respective results when considering the following hypotheses: 
$\mathbf{H}_{\mathbf{0}}: \quad$ There is no general opinion of the students regarding hybrid courses

$\mathbf{H}_{1}$ : $\quad$ The students have a preference towards taking hybrid courses

The null hypothesis $\left(\mathrm{H}_{0}\right)$ was compared to the alternative hypothesis $\left(\mathrm{H}_{1}\right)$ using a Chi-Squared analysis and assuming a baseline level of significance of $\alpha=0.05$. Therefore, any findings where the observed Chi-Squared value was greater than or equal to the critical value (based on the corresponding degrees of freedom and level of significance) would allow the null hypothesis to be rejected, thus indicating that there would be a maximum probability of 0.05 of achieving a Type I Error (i.e., falsely rejecting the null hypothesis and accepting the alternative position that students have a preference towards taking a hybrid course). To determine the Chi-Squared values for each testing scenario, the observed survey results were compared to an expected value based on the assumption that there was indifference between each of the possible answer choices; therefore, the average number of responses was chosen as the expected frequencies for each possible response. Testing was conducted individually for the freshmen/sophomore, junior/senior, senior, and graduate class levels, as well as a total comprehensive analysis for these class levels combined. Furthermore, testing included analyses pertaining to each of the survey options in addition to more segmented option groupings. Complete tabulations of these analyses are included in Appendices B and C for Questions 3 and 2, respectively.

When analyzing Question 3 (see Appendix B), the overall results for all class levels combined clearly indicated that the null hypothesis could be rejected with $\alpha=0.05$, which indicates that the students do have a statistically significant preference towards the course structure at this level of significance. The results were then analyzed further to determine whether the preference was for taking a hybrid course, or if it was more directly aimed at not taking a traditional course (i.e., note that an option was "don't care" to this question). Comparing the responses of choosing "hybrid" versus the combined total of "don't care" and "traditional" indicated a preference towards the "hybrid" structure for the total of all class levels, and the individual senior and graduate class levels at a level of significance of 0.05 ; however, this preference was only valid for the junior/senior class level with $\alpha=0.122$ and the freshmen/sophomore class level with $\alpha=0.695$ (i.e., there would be an approximate $69.5 \%$ likelihood of falsely rejecting the null hypothesis and assuming that the freshmen/sophomore class level clearly preferred a hybrid course structure). It again seems as though the students become more comfortable and independent in their work as they progress through the program and then clearly prefer the hybrid course structure. A further analysis grouped the "hybrid" and "don't care" respondents and compared these frequencies with those that chose the "traditional" course structure. These results were statistically significant with $\alpha=0.05$ for all individual class levels, thus indicating that there is only a 5\% likelihood of falsely accepting the notion that students prefer to not take a traditional course if given the option of having a hybrid course.

The survey results for Question 2 were then analyzed further to determine the likelihood of students taking another hybrid course based off of these experiences. A complete tabulation of these results is included in Appendix C. The students could choose between the answers of "yes", "maybe", "probably not", or "definitely not" for this question. Based on these results, the total of all class levels and each individual class level groupings clearly indicated that there was a preference towards the future choosing of a hybrid course with $\alpha=0.05$. When analyzing further and comparing the statistical significance of the students choosing "yes" or "maybe", it was acceptable to reject the null hypothesis for all class levels (combined and individually) that the students would take another hybrid course. Therefore, there is only a 5\% likelihood of falsely accepting the alternative hypothesis that students would take another hybrid course in the future.

\section{CONCLUSIONS}

Although the overall prior experience with the hybrid course structure varied amongst the students, most students seemed to be satisfied and would prefer hybrid courses. This conclusion was further supported with the statistical analysis that indicated students would prefer to take hybrid courses in the future. The hybrid course structure is improving, as evidenced with the positive feedback regarding the technical online presentation setup, but is still not perfect. For the online portion of the course, challenges remain regarding how to better engage the students into both discussions and the formation of a virtual community. Furthermore, because class time is reduced by one-half, the appropriate utilization of class time is unclear. For the courses that were the subject of this study, 
the proper inclusion of short case analyses, problem solving exercises, and open discussions with the professor may be applied with a proper balance of student presentation and lecture time.

Subjective feedback from the students was overwhelmingly positive and supported the notion that class time organization is a challenge. An additional common point that was addressed pertained to the students' discipline to study independently. Whereas the benefits of increased flexibility and the stimulation of independent thinking may be associated with hybrid courses, a student may struggle if he/she does not possess the personal discipline to study the online presentation components and participate in any online discussions. An approach to address this problem is cognitive domain taxonomy, which is a scheme of instructional outcomes that stress knowledge and intellectual outcomes that stress intellectual skill and comprehension application, analysis, synthesis, and evaluation. The intellectual skill can be measured by asking a few questions that are imbedded in the on-line portion of the lesson, whereby the student can see results of their responses. Comprehension and synthesis can then be measured with imbedded questioning on-line and problem solving and short case analyses in the classroom (Snowman, 2009). This means that, when there are questions imbedded in the on-line lesson and problem solving takes place in the classroom via short case studies, the concepts are reinforced through the experiences of using the material to solve problems.

A goal of hybrid course design may be to blend the benefits of the direct instruction format with the guided discovery approach. As evidenced with this paper, the proper use of technology for the online component and carefully structured in-class design may provide a hybrid course structure that encompasses the benefits of both approaches.

\section{FUTURE WORK}

In order to better incorporate the benefits of both the direct instruction format and the guided discovery approach, future work will consider the addition of an audio component to the hybrid course structure. Although the current format guided the students through the presentation slides and videos in an interactive manner, there may be instances that would benefit from additional comments from the instructor. Therefore, it would be possible to design the presentation slides without having to convey all information on the slides. Instead, the instructor could elaborate verbally on the audio file that could be played to augment the information contained on the slides. In addition to providing subject clarification benefits, this extension also may help mitigate the problem of class time organization. Given that the majority of students desired more verbal information from the instructor, including audio with the online component may be able to solve this problem. Furthermore, the ability to include spoken information in an audio file may lessen the needs of in-class lecture, thus allowing more time for the desired short case analyses, problem solving exercises, and open discussions with the professor. The inclusion of audio may further reduce the need to meet in the classroom and allow the students even more flexibility regarding how to schedule their academic endeavors. Finally, a more in-depth survey may be created and administered that would capture more details regarding hybrid course design and student preferences and allow for a richer blend of qualitative and statistical analyses.

\section{REFERENCES}

1. Bates, Constance, and Watson, Maida, (2008). "Re-learning Teaching Techniques to be Effective in Hybrid and Online Courses," Cambridge, Hollywood: Journal of American Academy of Business, Volume 13, Issue 1, pg. 38-44.

2. Clark, Lawrence J., (2001). "Web-based Teaching: A New Educational Paradigm,” Intercom, Volume 48, Number 5, pp. 20-21.

3. D’Orsie, Sharon M., and Day, Karen, (2006). “Ten Tips for Teaching a Web Course," Tech Directions, Feb. 2006, Volume 65, Issue 7, pg. 18-20.

4. El Mansour, Bassou, Mupinga, and Davidson M., (2007). "Students' Positive and Negative Experiences in Hybrid and Online Classes," College Student Journal, Volume 41, Number 1, March 2007, pg. 242-8.

5. Gargiulo, Richard, and Metcalf, Debbie, (2010). Teaching in Today's Inclusive Classroom, Cengage, p. 158. 
6. Hiltz, Starr Roxanne, and Turoff, Murray, (2005). "Education Goes Digital: The Evolution of Online Learning and the Revolution in Higher Education," Communications of the ACM, October 2005, Volume 48, Number 10, pp. 59-64.

7. Millison, Murray R. and Wilemon, David (2008), "Educational Quality Correlates of Online Graduate Management Education," Journal of Distance Education, Volume 22, Number 3, pp. 1-18.

8. Penrose, John, (2006). "Teaching The Essential Role Of Visualization In Preparing Instructions," Business Communication Quarterly, Volume 69, Number 4, pp. 411-417.

9. Snowman, Jack, McCowan, Rick, and Biehler, Robert (2009). Psychology Applied to Teaching, Boston, New York: Houghton Mifflin, p.567.

10. Terry, Neil, (2007). "Assessing Instruction Models for Master of Business Administration (MBA) Courses," Washington: Journal of Education for Business, Mar/Apr 2007, Volume 82, Issue 4, pp. 220225.

11. William Dylan, (2006). “Assessment: Learning Communities Can Use It to Engineer a Bridge Connecting Teaching and Learning," Journal of Staff Development, Winter 2006, Volume 27, Number 1, pp. 16-20.

12. Yelon, Stephen, (2006), "Face-to-Face or Online? Choosing the Medium in Blended Training," Performance Improvement, Volume 45, Issue 3, pp. 22-26.

13. Young, Jeffrey R., (2002). "Hybrid Teaching Seeks to End the Divide between Traditional and Online Instruction," The Chronicle of Higher Education, Volume 48, Number 28, A33-A34, Mr 22, 2002. 


\section{APPENDIX A}
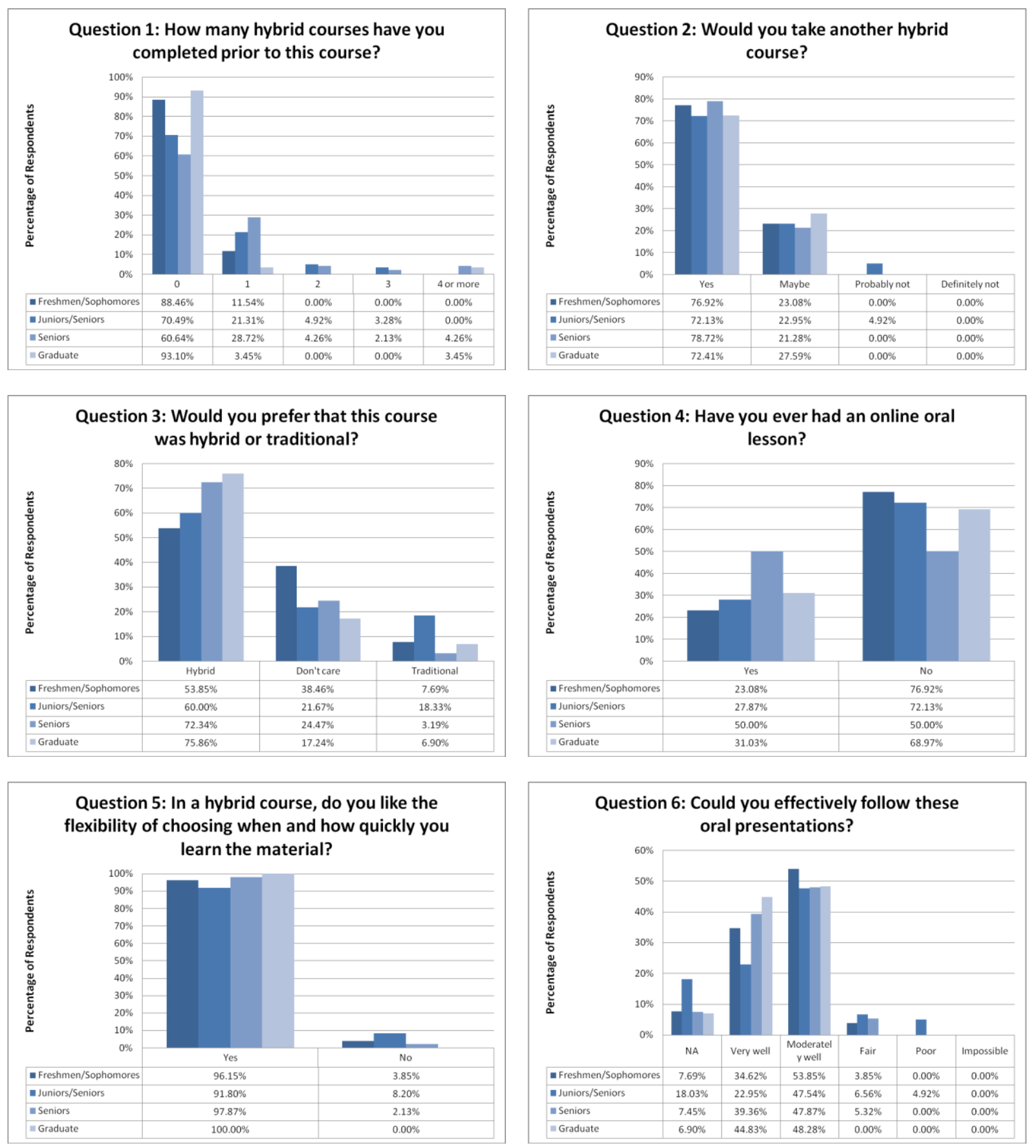

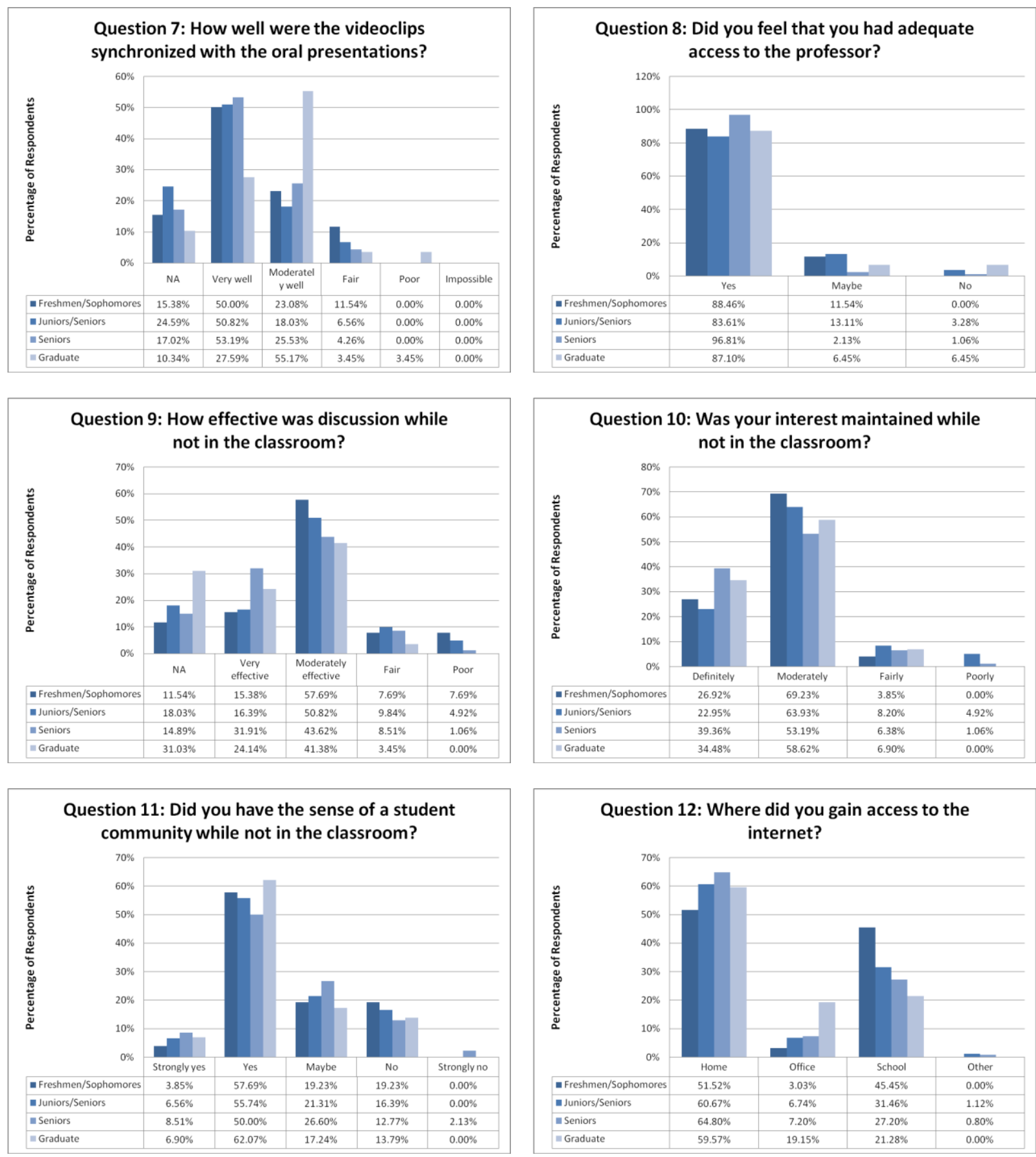

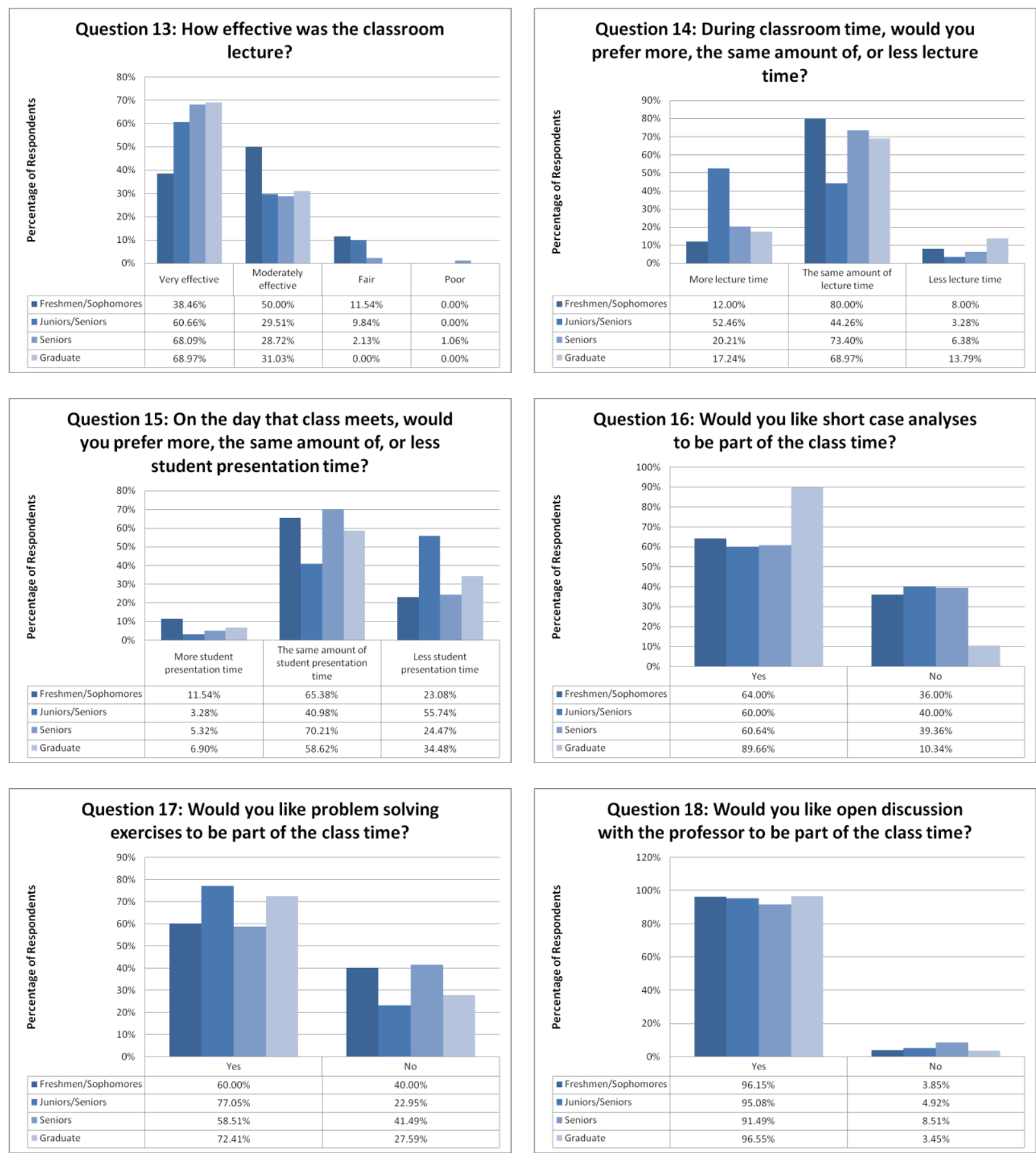


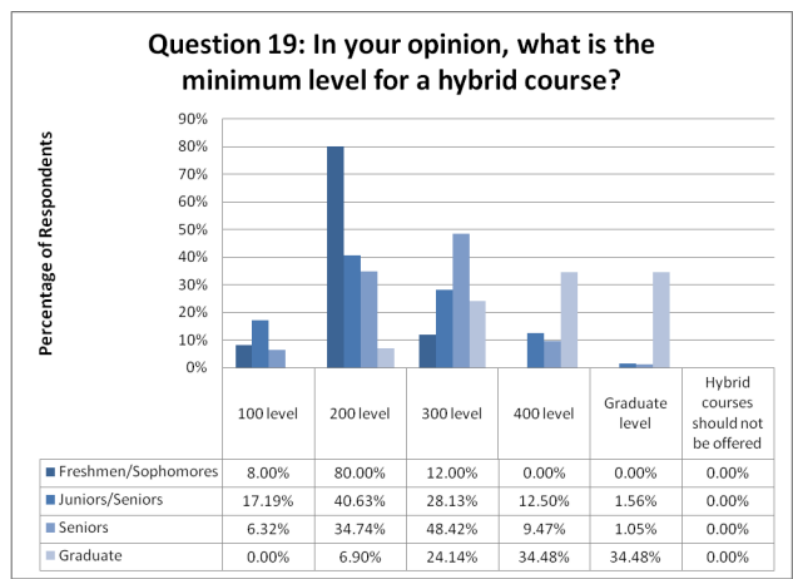




\section{APPENDIX B}

Question \#3: Would you prefer that this course was hybrid or traditional?

Class Level: Freshmen/Sophomores

\begin{tabular}{|c|c|c|c|c|c|c|c|c|}
\hline $\begin{array}{c}\text { Test } \\
\text { Number }\end{array}$ & Options & \begin{tabular}{|c}
$\begin{array}{c}\text { Observed } \\
\text { Results }\end{array}$ \\
\end{tabular} & \begin{tabular}{|c|}
$\begin{array}{c}\text { Expected } \\
\text { Results }\end{array}$ \\
\end{tabular} & $\begin{array}{c}\text { Observed } \\
\text { Chi-Squared }\end{array}$ & \begin{tabular}{|c|}
$\begin{array}{c}\text { Degrees of } \\
\text { Freedom }\end{array}$ \\
\end{tabular} & $\begin{array}{l}\text { Cricial } \\
\text { Value }\end{array}$ & Alpha & Conclusion \\
\hline \multirow{3}{*}{1} & Hybrid & 14 & 8.67 & \multirow{3}{*}{8.615} & \multirow{3}{*}{2} & \multirow{3}{*}{5.991} & \multirow{3}{*}{0.05} & \multirow{3}{*}{ Reject $\mathrm{H}_{0}$} \\
\hline & Don't Care & 10 & 8.67 & & & & & \\
\hline & Traditional & 2 & 8.67 & & & & & \\
\hline \multirow{2}{*}{2} & Hybrid & 14 & 13 & \multirow{2}{*}{0.1538} & \multirow{2}{*}{1} & \multirow{2}{*}{0.1537} & \multirow{2}{*}{0.695} & Accept $\mathrm{H}_{0}(\alpha=0.05)$ \\
\hline & Don't Care / Traditional & 12 & 13 & & & & & Reject $\mathrm{H}_{0}(\alpha=0.695)$ \\
\hline \multirow{2}{*}{3} & Hybrid / Don't Care & 24 & 13 & \multirow{2}{*}{18.615} & \multirow{2}{*}{1} & \multirow{2}{*}{3.841} & \multirow{2}{*}{0.05} & \multirow{2}{*}{ Reject $\mathrm{H}_{0}$} \\
\hline & Traditional & 2 & 13 & & & & & \\
\hline
\end{tabular}

Class Level: Juniors/Seniors

\begin{tabular}{|c|c|c|c|c|c|c|c|c|}
\hline $\begin{array}{c}\text { Test } \\
\text { Number }\end{array}$ & Options & $\begin{array}{c}\text { Observed } \\
\text { Results }\end{array}$ & \begin{tabular}{|c|} 
Expected \\
Results
\end{tabular} & \begin{tabular}{|c|} 
Observed \\
Chi-Squared
\end{tabular} & $\begin{array}{c}\text { Degrees of } \\
\text { Freedom }\end{array}$ & $\begin{array}{l}\text { Cricial } \\
\text { Value }\end{array}$ & Alpha & Conclusion \\
\hline \multirow{3}{*}{1} & Hybrid & 36 & 20 & \multirow{3}{*}{19.300} & \multirow{3}{*}{2} & \multirow{3}{*}{5.991} & \multirow{3}{*}{0.05} & \multirow{3}{*}{ Reject $\mathrm{H}_{0}$} \\
\hline & Don't Care & 13 & 20 & & & & & \\
\hline & Traditional & 11 & 20 & & & & & \\
\hline \multirow{2}{*}{2} & Hybrid & 36 & 30 & \multirow{2}{*}{2.400} & \multirow{2}{*}{1} & \multirow{2}{*}{2.391} & \multirow{2}{*}{0.122} & Accept $\mathrm{H}_{0}(\alpha=0.05)$ \\
\hline & Don't Care / Traditional & 24 & 30 & & & & & Reject $\mathrm{H}_{0}(\alpha=0.122)$ \\
\hline \multirow{2}{*}{3} & Hybrid / Don't Care & 49 & 30 & \multirow{2}{*}{24.067} & \multirow{2}{*}{1} & \multirow{2}{*}{3.841} & \multirow{2}{*}{0.05} & \multirow{2}{*}{ Reject $\mathrm{H}_{0}$} \\
\hline & Traditional & 11 & 30 & & & & & \\
\hline
\end{tabular}

Class Level: Seniors

\begin{tabular}{|c|c|c|c|c|c|c|c|c|}
\hline \begin{tabular}{|c|} 
Test \\
Number \\
\end{tabular} & Options & \begin{tabular}{|c|}
$\begin{array}{c}\text { Observed } \\
\text { Results }\end{array}$ \\
\end{tabular} & \begin{tabular}{|c|} 
Expected \\
Results
\end{tabular} & \begin{tabular}{|c|} 
Observed \\
Chi-Squared
\end{tabular} & \begin{tabular}{|c|}
$\begin{array}{c}\text { Degrees of } \\
\text { Freedom }\end{array}$ \\
\end{tabular} & \begin{tabular}{|l|} 
Cricial \\
Value \\
\end{tabular} & Alpha & Conclusion \\
\hline \multirow{3}{*}{1} & Hybrid & 68 & 31.33 & \multirow{3}{*}{70.745} & \multirow{3}{*}{2} & \multirow{3}{*}{5.991} & \multirow{3}{*}{0.05} & \multirow{3}{*}{ Reject $\mathrm{H}_{0}$} \\
\hline & Don't Care & 23 & 31.33 & & & & & \\
\hline & Traditional & 3 & 31.33 & & & & & \\
\hline \multirow{2}{*}{2} & Hybrid & 68 & 47 & \multirow{2}{*}{18.766} & \multirow{2}{*}{1} & \multirow{2}{*}{3.841} & \multirow{2}{*}{0.05} & \multirow{2}{*}{ Reject $\mathrm{H}_{0}$} \\
\hline & Don't Care / Traditional & 26 & 47 & & & & & \\
\hline \multirow{2}{*}{3} & Hybrid / Don't Care & 91 & 47 & \multirow{2}{*}{82.383} & \multirow{2}{*}{1} & \multirow{2}{*}{3.841} & \multirow{2}{*}{0.05} & \multirow{2}{*}{ Reject $\mathrm{H}_{0}$} \\
\hline & Traditional & 3 & 47 & & & & & \\
\hline
\end{tabular}

Class Level: Graduate

\begin{tabular}{|c|c|c|c|c|c|c|c|c|}
\hline $\begin{array}{c}\text { Test } \\
\text { Number }\end{array}$ & Options & \begin{tabular}{|c|}
$\begin{array}{c}\text { Observed } \\
\text { Results }\end{array}$ \\
\end{tabular} & \begin{tabular}{|c|} 
Expected \\
Results
\end{tabular} & $\begin{array}{c}\text { Observed } \\
\text { Chi-Squared }\end{array}$ & \begin{tabular}{|c|}
$\begin{array}{c}\text { Degrees of } \\
\text { Freedom }\end{array}$ \\
\end{tabular} & $\begin{array}{l}\text { Cricial } \\
\text { Value }\end{array}$ & Alpha & Conclusion \\
\hline \multirow{3}{*}{1} & Hybrid & 22 & 9.67 & \multirow{3}{*}{24.069} & \multirow{3}{*}{2} & \multirow{3}{*}{5.991} & \multirow{3}{*}{0.05} & \multirow{3}{*}{ Reject $\mathrm{H}_{0}$} \\
\hline & Don't Care & 5 & 9.67 & & & & & \\
\hline & Traditional & 2 & 9.67 & & & & & \\
\hline \multirow{2}{*}{2} & Hybrid & 22 & 14.5 & \multirow{2}{*}{7.759} & \multirow{2}{*}{1} & \multirow{2}{*}{3.841} & \multirow{2}{*}{0.05} & \multirow{2}{*}{ Reject $\mathrm{H}_{0}$} \\
\hline & Don't Care / Traditional & 7 & 14.5 & & & & & \\
\hline \multirow{2}{*}{3} & Hybrid / Don't Care & 27 & 14.5 & \multirow{2}{*}{21.552} & \multirow{2}{*}{1} & \multirow{2}{*}{3.841} & \multirow{2}{*}{0.05} & \multirow{2}{*}{ Reject $\mathrm{H}_{0}$} \\
\hline & Traditional & 2 & 14.5 & & & & & \\
\hline
\end{tabular}

Class Level: Total of All Class Levels

\begin{tabular}{|c|c|c|c|c|c|c|c|c|}
\hline $\begin{array}{c}\text { Test } \\
\text { Number }\end{array}$ & Options & \begin{tabular}{|c|}
$\begin{array}{c}\text { Observed } \\
\text { Results }\end{array}$ \\
\end{tabular} & \begin{tabular}{|c|}
$\begin{array}{c}\text { Expected } \\
\text { Results }\end{array}$ \\
\end{tabular} & \begin{tabular}{|c|} 
Observed \\
Chi-Squared
\end{tabular} & \begin{tabular}{|c|}
$\begin{array}{c}\text { Degrees of } \\
\text { Freedom }\end{array}$ \\
\end{tabular} & $\begin{array}{l}\text { Cricial } \\
\text { Value }\end{array}$ & Alpha & Conclusion \\
\hline \multirow{3}{*}{1} & Hybrid & 140 & 69.67 & \multirow{3}{*}{114.325} & \multirow{3}{*}{2} & \multirow{3}{*}{5.991} & \multirow{3}{*}{0.05} & \multirow{3}{*}{ Reject $\mathrm{H}_{0}$} \\
\hline & Don't Care & 51 & 69.67 & & & & & \\
\hline & Traditional & 18 & 69.67 & & & & & \\
\hline \multirow{2}{*}{2} & Hybrid & 140 & 104.5 & \multirow{2}{*}{24.120} & \multirow{2}{*}{1} & \multirow{2}{*}{3.841} & \multirow{2}{*}{0.05} & \multirow{2}{*}{ Reject $\mathrm{H}_{0}$} \\
\hline & Don't Care / Traditional & 69 & 104.5 & & & & & \\
\hline \multirow{2}{*}{3} & Hybrid / Don't Care & 191 & 104.5 & \multirow{2}{*}{143.201} & \multirow{2}{*}{1} & \multirow{2}{*}{3.841} & \multirow{2}{*}{0.05} & \multirow{2}{*}{ Reject $\mathrm{H}_{0}$} \\
\hline & Traditional & 18 & 104.5 & & & & & \\
\hline
\end{tabular}




\section{APPENDIX C}

Question \#2: Would you take another hybrid course?

Class Level: Freshmen/Sophomores

\begin{tabular}{|c|c|c|c|c|c|c|c|c|}
\hline $\begin{array}{c}\text { Test } \\
\text { Number }\end{array}$ & Options & $\begin{array}{c}\text { Observed } \\
\text { Results }\end{array}$ & $\begin{array}{c}\text { Expected } \\
\text { Results }\end{array}$ & $\begin{array}{c}\text { Observed } \\
\text { Chi-Squared }\end{array}$ & \begin{tabular}{|c|} 
Degrees of \\
Freedom
\end{tabular} & $\begin{array}{l}\text { Cricial } \\
\text { Value }\end{array}$ & Alpha & Conclusion \\
\hline \multirow{4}{*}{1} & Yes & 20 & 6.50 & \multirow{4}{*}{41.077} & \multirow{4}{*}{3} & \multirow{4}{*}{7.815} & \multirow{4}{*}{0.05} & \multirow{4}{*}{ Reject $\mathrm{H}_{0}$} \\
\hline & Maybe & 6 & 6.50 & & & & & \\
\hline & Probably Not & 0 & 6.50 & & & & & \\
\hline & Definitely Not & 0 & 6.50 & & & & & \\
\hline \multirow{2}{*}{2} & Yes & 20 & 13 & \multirow{2}{*}{7.538} & \multirow{2}{*}{1} & \multirow{2}{*}{3.841} & \multirow{2}{*}{0.05} & \multirow{2}{*}{ Reject $\mathrm{H}_{0}$} \\
\hline & Maybe & 6 & 13 & & & & & \\
\hline
\end{tabular}

Class Level: Juniors/Seniors

\begin{tabular}{|c|c|c|c|c|c|c|c|c|}
\hline $\begin{array}{c}\text { Test } \\
\text { Number }\end{array}$ & Options & \begin{tabular}{|c|} 
Observed \\
Results
\end{tabular} & \begin{tabular}{|c|}
$\begin{array}{c}\text { Expected } \\
\text { Results }\end{array}$ \\
\end{tabular} & \begin{tabular}{c|} 
Observed \\
Chi-Squared \\
\end{tabular} & $\begin{array}{c}\begin{array}{c}\text { Degrees of } \\
\text { Freedom }\end{array} \\
\end{array}$ & $\begin{array}{l}\text { Cricial } \\
\text { Value }\end{array}$ & Alpha & Conclusion \\
\hline \multirow{4}{*}{1} & Yes & 44 & 15.25 & \multirow{4}{*}{79.393} & \multirow{4}{*}{3} & \multirow{4}{*}{7.815} & \multirow{4}{*}{0.05} & \multirow{4}{*}{ Reject $\mathrm{H}_{0}$} \\
\hline & Maybe & 14 & 15.25 & & & & & \\
\hline & Probably Not & 3 & 15.25 & & & & & \\
\hline & Definitely Not & 0 & 15.25 & & & & & \\
\hline \multirow{2}{*}{2} & Yes & 44 & 29 & \multirow{2}{*}{15.517} & \multirow{2}{*}{1} & \multirow{2}{*}{3.841} & \multirow{2}{*}{0.05} & \multirow{2}{*}{ Reject $\mathrm{H}_{0}$} \\
\hline & Maybe & 14 & 29 & & & & & \\
\hline \multirow{2}{*}{3} & Yes & 44 & 30.5 & \multirow{2}{*}{11.951} & \multirow{2}{*}{1} & \multirow{2}{*}{3.841} & \multirow{2}{*}{0.05} & \multirow{2}{*}{ Reject $\mathrm{H}_{0}$} \\
\hline & Maybe / Probably Not & 17 & 30.5 & & & & & \\
\hline
\end{tabular}

Class Level: Seniors

\begin{tabular}{|c|c|c|c|c|c|c|c|c|}
\hline $\begin{array}{c}\text { Test } \\
\text { Number }\end{array}$ & Options & \begin{tabular}{|c|} 
Observed \\
Results
\end{tabular} & $\begin{array}{c}\text { Expected } \\
\text { Results }\end{array}$ & $\begin{array}{c}\text { Observed } \\
\text { Chi-Squared }\end{array}$ & \begin{tabular}{|c|} 
Degrees of \\
Freedom
\end{tabular} & $\begin{array}{l}\text { Cricial } \\
\text { Value }\end{array}$ & Alpha & Conclusion \\
\hline \multirow{4}{*}{1} & Yes & 74 & 23.5 & \multirow{4}{*}{156.043} & \multirow{4}{*}{3} & \multirow{4}{*}{7.815} & \multirow{4}{*}{0.05} & \multirow{4}{*}{ Reject $\mathrm{H}_{0}$} \\
\hline & Maybe & 20 & 23.5 & & & & & \\
\hline & Probably Not & 0 & 23.5 & & & & & \\
\hline & Definitely Not & 0 & 23.5 & & & & & \\
\hline \multirow{2}{*}{2} & Yes & 74 & 47 & \multirow{2}{*}{31.021} & \multirow{2}{*}{1} & \multirow{2}{*}{3.841} & \multirow{2}{*}{0.05} & \multirow{2}{*}{ Reject $\mathrm{H}_{0}$} \\
\hline & Maybe & 20 & 47 & & & & & \\
\hline
\end{tabular}

Class Level: Graduate

\begin{tabular}{|c|c|c|c|c|c|c|c|c|}
\hline $\begin{array}{c}\text { Test } \\
\text { Number }\end{array}$ & Options & $\begin{array}{c}\text { Observed } \\
\text { Results }\end{array}$ & \begin{tabular}{|c|} 
Expected \\
Results
\end{tabular} & $\begin{array}{c}\text { Observed } \\
\text { Chi-Squared }\end{array}$ & $\begin{array}{c}\text { Degrees of } \\
\text { Freedom }\end{array}$ & $\begin{array}{l}\text { Cricial } \\
\text { Value }\end{array}$ & Alpha & Conclusion \\
\hline \multirow{4}{*}{1} & Yes & 21 & 7.25 & \multirow{4}{*}{40.655} & \multirow{4}{*}{3} & \multirow{4}{*}{7.815} & \multirow{4}{*}{0.05} & \multirow{4}{*}{ Reject $\mathrm{H}_{0}$} \\
\hline & Maybe & 8 & 7.25 & & & & & \\
\hline & Probably Not & 0 & 7.25 & & & & & \\
\hline & Definitely Not & 0 & 7.25 & & & & & \\
\hline \multirow{2}{*}{2} & Yes & 21 & 14.5 & \multirow{2}{*}{5.828} & \multirow{2}{*}{1} & \multirow{2}{*}{3.841} & \multirow{2}{*}{0.05} & \multirow{2}{*}{ Reject $\mathrm{H}_{0}$} \\
\hline & Maybe & 8 & 14.5 & & & & & \\
\hline
\end{tabular}

Class Level: Total of All Class Levels

\begin{tabular}{|c|c|c|c|c|c|c|c|c|}
\hline $\begin{array}{c}\text { Test } \\
\text { Number }\end{array}$ & Options & \begin{tabular}{|c|}
$\begin{array}{c}\text { Observed } \\
\text { Results }\end{array}$ \\
\end{tabular} & \begin{tabular}{|c|}
$\begin{array}{c}\text { Expected } \\
\text { Results }\end{array}$ \\
\end{tabular} & \begin{tabular}{|c|} 
Observed \\
Chi-Squared
\end{tabular} & $\begin{array}{c}\text { Degrees of } \\
\text { Freedom }\end{array}$ & $\begin{array}{l}\text { Cricial } \\
\text { Value }\end{array}$ & Alpha & Conclusion \\
\hline \multirow{4}{*}{1} & Yes & 159 & 52.5 & \multirow{4}{*}{315.600} & \multirow{4}{*}{3} & \multirow{4}{*}{7.815} & \multirow{4}{*}{0.05} & \multirow{4}{*}{ Reject $\mathrm{H}_{0}$} \\
\hline & Maybe & 48 & 52.5 & & & & & \\
\hline & Probably Not & 3 & 52.5 & & & & & \\
\hline & Definitely Not & 0 & 52.5 & & & & & \\
\hline \multirow{2}{*}{2} & Yes & 159 & 103.5 & \multirow{2}{*}{59.522} & \multirow{2}{*}{1} & \multirow{2}{*}{3.841} & \multirow{2}{*}{0.05} & \multirow{2}{*}{ Reject $\mathrm{H}_{0}$} \\
\hline & Maybe & 48 & 103.5 & & & & & \\
\hline \multirow{2}{*}{3} & Yes & 159 & 105 & \multirow{2}{*}{55.543} & \multirow{2}{*}{1} & \multirow{2}{*}{3.841} & \multirow{2}{*}{0.05} & \multirow{2}{*}{ Reject $\mathrm{H}_{0}$} \\
\hline & Maybe / Probably Not & 51 & 105 & & & & & \\
\hline
\end{tabular}




\section{NOTES}

